\title{
Risk Assessment of Virtual Enterprise Based on the Fuzzy Comprehensive Evaluation Method
}

\author{
Gang Liu, Jiao Zhang,Wangmin Zhang and Xian Zhou \\ School of Business, Hubei University, P.R. China, 430062
}

\begin{abstract}
For the organizational specialty of a virtual enterprise, the enterprise faces more complicated risk management problems than those in the traditional enterprise. So, to analyze the main affecting factors about the risk and to assess deeply the level of risk management for a virtual enterprise have their important and realistic significance. Based on the aspect of life cycle, this paper divides the cycle of a virtual enterprise into four periods, which are recognition period, construction period, operation period, and termination period. After that, this paper analyzes the possible risks that occur in each period and establishes a set of risk indicator system. According to these, the paper constructs a risk assessment model based on the fuzzy mathematic theory, then adopts this model to evaluate the project risks of virtual enterprise, and testifies its effectiveness through an example finally.
\end{abstract}

\section{Introduction}

Along with the integration of world economy and the revolution of the information technology, the competition between the enterprises' external markets becomes more intense. In order to response the market opportunity in time, meet the market demand and obtain more market shares, many enterprises make the virtual enterprise as a realistic choice for a new organization form. Virtual enterprise can help the enterprise response the market flexibly. However, it also contains many risk factors inevitably. Risks and opportunities coexist in virtual enterprise, and the success of risk management ensures the successful operation of virtual enterprise. Therefore, the risk management of virtual enterprise now becomes the focus of people's attention.

Nowadays, scholars in and abroad have done some researches on risk of virtual enterprise. References [1-2] mainly proposed relative risk management measures in

Please use the following format when citing this chapter

I.iu, G., Zhang, J., Thang, W., Zhou, X., 2007, in IlIP International I'ederation for Information Processing, Volume 251, Integration and Innovation Orient to F-Socicty Volume1, Wang, W. (Fds), (Boston: Springer), pp. 58-66. 
terms of the systematic analysis of risk factors in virtual enterprise, and focused on how to supervise its risks effectively and timely. But risk analysis is only the basis of risk management and risk supervision is only the part of risk control too. The focus of risk management about virtual enterprise is risk assessment. There are also many scholars have done some effective researches on risk assessment of virtual enterprise from different aspects, reference [3] constructed a set of index system which adapted to the risk assessment of virtual enterprise based on analyzing the main factors that should be considered in the process of risk assessment. Then it gave index value and assessor's subjective sensation value, and introduced the fuzzy and multi-attributed decision based on the expected value to get the prior order of the synthetic choice about the virtual enterprise's solutions. According to the character of having project as the organization model, considering the influence from the project time factor to the whole risk, reference [4] adopted a model called PERT to construct the risk assessment model of virtual enterprise based on the correspondence of the end time in a process and the fuzzy description by the process to the risk level.

This paper connects the risk factor of virtual enterprise with its life cycle, and recognizes the risk factor of virtual enterprise during its different developing phases with detailed analysis. After that, it establishes a series of indexes which adapt to assess the risk factor of virtual enterprise in terms of its lifecycle. It refers to the application circumstances of fuzzy method which can be used in risk problems of virtual enterprise, so it adopts the fuzzy mathematics theory to establish a model to evaluate the risk of virtual enterprise. Finally, it uses the fuzzy comprehensive evaluation method based on the risk factors to appraise the risk of virtual enterprise, and testifies its effectiveness through an actual example.

\section{The basic concept of virtual enterprise and its life cycle theory}

The concept of "Virtual Enterprise" was firstly put forwarded by Iacocco Institute of Lehigh University in American in the report of "China's Manufacturing Industry Development Strategies in the 21 st Century" ${ }^{\mathbf{I} s 1}$. The virtual enterprise can adjust the strategy in order to adapt to the changed market timely, and can integrate all the advantages of the enterprises to reach "win-win". So the idea of "Virtual Enterprise" is greatly praised as soon as it was put forward. At present, there is no clear and agreeable definition of virtual enterprise, many scholars think it is equal to the dynamic alliance, and consider it is a temporary enterprise union which is formed by several enterprises in order to seize and take advantage of rapidly changing market opportunities through information technologies. Once the market opportunities do not exists, the enterprise union will disorganize ${ }^{[6-7]}$.

The virtual enterprise emerges when the market opportunities exists and it selfdisorganizes when the opportunities disappears. So the life cycle of virtual enterprise is obvious. After researches and conclusions from several relevant references ${ }^{[8-9]}$, this paper considers that it is suitable to divide the virtual enterprise's construction and operation into four periods, which are recognition, construction, operation and termination period. The recognition period is the start of enterprise. The main tasks in this period are the recognition, evaluation and selection of the market 
opportunities. Main contents of construction period include recognition and selection of the partners, designation of the organizational operation model, establishment of interest/risk institution and designation of the information system. Main contents of operation period include the distribution and coordination of tasks, cost control, performance monitoring, risk management and credit management. In termination period, along with the disappearing of opportunities and the separating of partners, the virtual enterprise corrupts. Main contents of termination period include the terminal recognition and disposal of checking out.

The life cycle of enterprise is shown as figure 1:

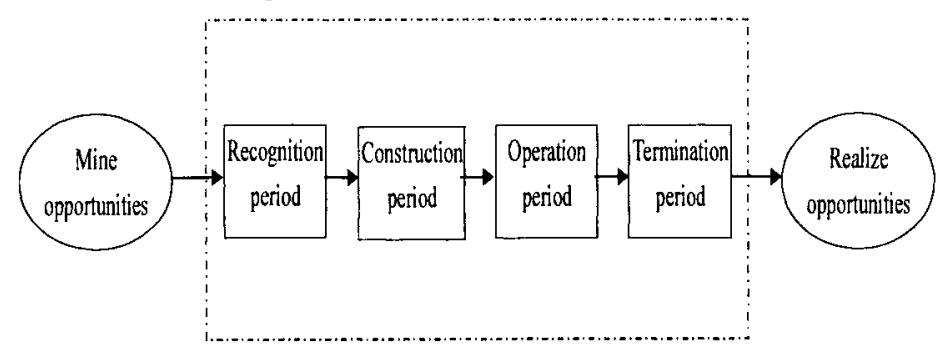

Fig. 2, The life cycle of enterprise

\section{The index system of virtual enterprise's risk assessment}

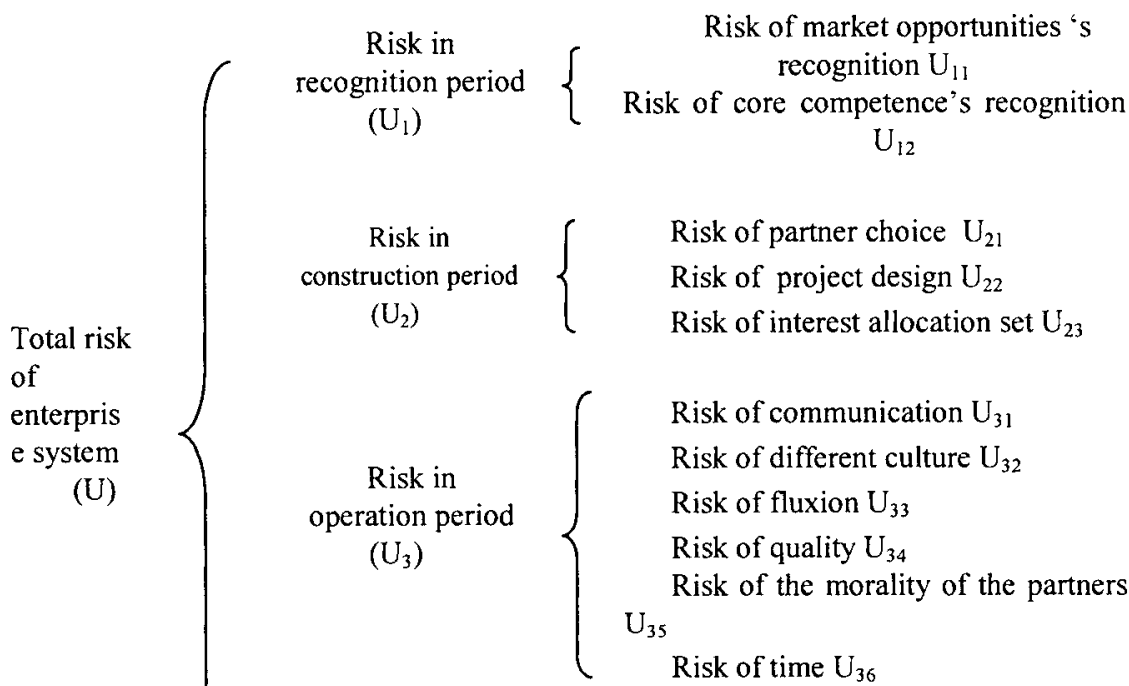

Risk in operation period $\left(\mathrm{U}_{4}\right)$

Risk of interest allocation $\mathrm{U}_{41}$

Risk of clearing $U_{42}$ 
Fig. 2, the virtual enterprise's internal risk assessment system

The risk of virtual enterprise is brought by two parts generally. The first is from external factors, such as political risk, market risk, finance risk, etc. These are called external risks which enterprises can not control.

The second is the risks leaded by the enterprise's activities which can be controlled through proper strategies, it is internal risk. This paper recognizes the internal risks based on the virtual enterprise's life cycle, and constructs the virtual enterprise's internal risk assessment system that is shown in figure 2.

Figure 2 divides the index system of an assessment of inner risk into 3 layers, and considers the risks in recognition period, construction period, operation period and termination period synthetically. Each layer has its own sub-index.

\subsection{Risk in recognition period}

(1) Risk of market opportunity recognition, which means that the core enterprises misunderstand the low-valued market opportunity as the promising market opportunity because of collecting inaccurate information or choosing wrong analysis tools.

(2) Risk of core competence recognition, which means the risk that the core enterprise assesses its own core competences highly or lowly so that it leads to a wrong choice in the realization of the market opportunity.

\subsection{Risk in construction period}

(1) Risk of partner choice, which means the loss caused by the improper choice of partner, and it leads to the virtual enterprise to change partner or disorganizes in the midway.

(2) Risk of cooperate project design, which means unreasonable task allocation or improper resource integration, and it leads to higher operation cost or the loss caused by the partner who can not finish the task in time.

(3) Risk of interest allocation set, which means the interest allocation solution set by the core enterprise is unreasonable, and it leads to the loss of the partners' enthusiasm or the quit of the partner in the midway. Hence it leads to the risk of the virtual enterprise's disorganization in the midway.

\subsection{Risk in operation period}

(1) Risk of communication, which means the alliance members' insufficient communication, it leads the dislocation of process assignment or causes other losses.

(2) Risk of different culture, which means the different culture background, it leads to the confliction which makes the virtual enterprise disorganize in the midway.

(3) Risk of fluxion, which means the partners can join or leave the organization freely as the virtual enterprise is an open organization, and this fluidity may lead to the project shelved or disorganized, it is also disadvantage to the knowledge accumulation.

(4) Risk of quality, each partner's policy and level of quality may be different, if one's quality has problem, it will affect the whole product's quality. 
(5) Risk of the morality of the partners, which means the result of a possibility that each member uses its advantages to get self-benefit maximized might harm the others.

(6) Risk of time, because the starting time of information processing is inflexible to each member, the member may not finish the task in the planning time.

\subsection{Risk in termination period}

(1) Risk of interest allocation, which means the interest allocation is unreasonable or the law affairs may be caused by not executing the allocation plan.

(2) Risk of settlement, as the virtual enterprise is composed by a contract made by the enterprises in alliance, and sometimes the ownership is not determinate, so it may cause law affairs during the financial settlement period.

\section{Fuzzy comprehensive evaluation model based on risk factors}

Risk assessment is the process to evaluate the possibility of a recognized risk and its loss, so that the enterprise will be able to take effective measures to prevent and control it. It is known that the external risk is uncontrollable, so this paper only assesses the internal risks of virtual enterprise based on its life cycle.

In the risk assessment system that it has been constructed above, the referred assessment indicators are hard to be accurate and numerical. Therefore, this paper adopts the fuzzy comprehensive evaluation method based on the risk factors to evaluate the project risk of virtual enterprise ${ }^{[10-11]}$. The basic idea is to solve the above 4 determined factors, and then to integrate the risk factors to get the total system factors. According to the standard of probability classification, if the happened probability from a pre-designed rule is less than $30 \%$, the happened probability of the risk is pimping. While, if it is more than $70 \%$, the happened probability of the risk is great. So it is generally believed that if the total factor is above $70 \%$, the virtual enterprise's project has a higher risk and a low risk if it is less than $30 \%$ and between them the project has a middle risk.

According to the definition of risk, risk $\mathrm{R}$ is not only the function of the incident probability $\mathrm{P}$ of risk events, but also the function of the consequence $\mathrm{C}$ of it. This point is easier to be understood that, although something is of great probability, it costs little expense if it happens, so it is of low risk. On the contrary, something happens occasionally, but it costs much if it occurs, so it is risky. This relationship can be described as a function of $R=f(P, C)$. Let $P_{f}$ be the probability of the event fails, $P_{s}$ be the probability of the event succeeds, $C_{f}$ be the influent degree of the failed event and $C_{s}$ be the influent degree of the success event, then the risk function can be described as follows:

$R_{f}=1$-unhappened probability of risk event $\times$ the probability of its consequence

$$
\begin{aligned}
& =1-P_{s} C_{s} \\
& =1-\left(1-P_{f}\right)\left(1-C_{f}\right) \\
& =P_{f}+C_{f}-P_{f} C_{f} .
\end{aligned}
$$

In those, $R_{f}$ is the risk factor. 


\subsection{The determine of $P_{f}$}

Since this system is a hierarchical structure system, it can be analyzed by analytic hierarchy process ${ }^{[12]}$ to determine the influent degree of each factor to the failure of the project. Let $A_{i}$ be the subsystem $i, A_{i}=\left(a_{1}, a_{2}, \ldots, a_{n}\right)$, and $n$ is the number of the factors in the subsystem $i$.

Let $B=\left(b_{1}, b 2, b 3, b 4, b 5\right)=(0.1,0.3,0.5,0.7,0.9)$ be the magnitude of assessment for each factor. It is determined by experts. For example, the experts consider that $a_{i}$ belongs to $b_{j}$. Lete $e_{i j}$ be the total number of the experts who consider $a_{i}$ belong to $b_{j}$ divided by the total number of attended experts. $(i=1,2, \ldots, n, j$ $=1,2,3,4,5)$. So the failed probability is as follows:

$$
P_{j}=\sum_{i=1}^{n} \sum_{j=1}^{5}\left(a_{i} e_{i j} b_{j}\right)=A E B^{T}
$$

\subsection{The fuzzy comprehensive evaluation method of $C_{f}$}

For the estimation to the influent degree of the risk event's consequence has great uncertainty, so the $C_{f}$ is estimated by the fuzzy comprehensive evaluation method.

(1) Establishment of the set of factors

The set of factors is a set of indexes composed by each index of predetermined assessment objects, so, according to the assessment index system above, the assessment index set is as follows:

The first layer of index set: $U=\left\{U_{1}, U_{2}, U_{3}, U 4\right\}$

The second layer of index set: $U_{i}=\left\{U_{i 1} \ldots U_{i n}\right\}\left(U_{i n}\right.$ is the $n$th factor in $\left.U_{i}\right)$

(2) Determination of the assessing set

The assessing set is the set composed by total assessment which might be done by the assessors to the assessed objects. According to the influent degree of failure, the set can be divided as $\mathrm{V}=\{$ lower, low, middle, notable, high $\}$, and it is given the value of $\mathrm{V}=\left\{\begin{array}{lll}0.1, & 0.3,0.5,0.7,0.9\end{array}\right\}$

(3) Determination of the weight of each factor

The weight is the important degree of one index in the whole index system. This system is a hierarchically structural system, so the determination of the weight of each factor can be done by the analytic hierarchy process. Comparing with each two factors can obtain the compared matrix, then, by the solution of the eigenvalue of this matrix, the weight set can be gotten. The effectiveness of the weights though the coherence verification can be ensured. By using the analytic hierarchy process, the weight set of the first subsystem $A=\left\{A_{1}, A_{2}, A_{3}, A_{4}\right\}$ can be found, and the weight corresponding to each subsystem factor is $A_{1}=\left\{a_{i 1}, \ldots, a_{i n}\right\}$, here $i$ is from 1 to $4, n$ is the number of the factors corresponding to each subsystem.

(4) The fuzzy comprehensive evaluation method

By using the method of Delphi and consulting with the assessment set $\mathrm{V}$ to evaluate $U_{i n}$, the fuzzy comprehensive evaluated matrix $R_{i}$ in each subsystem is solved. The synthetic assessment matrix for factors in the ith subsystem is $H_{i}=A_{i} R_{i}$ $=\left\{\mathrm{h}_{1}, \mathrm{~h}_{2}, \mathrm{~h}_{3}, \mathrm{~h}_{4}, \mathrm{~h}_{5}\right\}(\mathrm{i}=1,2,3,4)$. By normalizing $\mathrm{H}_{\mathrm{i}}$ to be $\bar{h}_{i}=h_{i} / \sum_{j=1}^{5} h_{j}$, 
64 Risk Assessment of Virtual Enterprise Based on the Fuzzy Comprehensive Evaluation

the $\tilde{H}_{i}=\left(\tilde{h}_{1} \tilde{h}_{2} \tilde{h}_{3} \bar{h}_{4} \bar{h}_{5}\right)$ is gotten. So the influent degree to the failure of a project in the virtual enterprise cab be expressed by

$$
C_{f}=\tilde{H} V^{T}=0.1 h_{1}+0.3 h_{2}+0.5 h_{3}+0.7 h_{4}+0.9 h_{5} .
$$

\subsection{Calculation of risk factor $R_{f}$}

According to $R_{f}=P_{f}+C_{f}-P_{f} C_{f}$ the risk factor $R_{f i}$ of each subsystem is found out. As this system is a two layer of hierarchical structure, so the total risk factor $R_{f}$ can be determined by the summarizing of the risk though the follow formula after solving each subsystem's risk factor:

$$
R_{f}=\sum_{i=1}^{n} R_{f} A_{i}
$$

$R_{f i}$ is the risk factor in the $i t h$ subsystem, $A_{i}$ is the weight of the $i t h$ subsystem.

\section{An example}

One virtual enterprise plans to use fuzzy comprehensive evaluation method based on the risk factors to evaluate its project's risk. Taking the risk in construction period as an example, there are 10 experts to evaluate the probability of risk of partner choice, risk of cooperate project design, risk of benefit allocation, according to the assessing set V. After the statistic classification, the result is gotten as follows:

$$
E_{2}=\left[\begin{array}{ccccc}
0.1 & 0.7 & 0.2 & 0 & 0 \\
0.1 & 0.3 & 0.5 & 0.1 & 0 \\
0.2 & 0.6 & 0.2 & 0 & 0
\end{array}\right]
$$

$A_{2}=\left(\begin{array}{lll}0.4 & 0.30 .3\end{array}\right)$ is determined by the analytic hierarchy process, then the failed probability in the constructed period is calculated as follows:

$$
P_{f 2}=A_{2} E_{2} B^{T}=0.344
$$

The fuzzy assessing matrix of the influent degree to the failed result of each risk in the construction period is gotten by the experts scoring method as follows:

$$
R_{2}=\left[\begin{array}{ccccc}
0.1 & 0.4 & 0.2 & 0.3 & 0 \\
0.2 & 0.2 & 0.3 & 0.2 & 0.1 \\
0.2 & 0.4 & 0.3 & 0.1 & 0
\end{array}\right]
$$


The weight of each factor in this period $A_{2}=\left(\begin{array}{lll}0.5 & 0.30 .2\end{array}\right)$ though analytic hierarchy process, so the synthetic assessment matrix $H_{2}=A_{2} R_{2}=\left(\begin{array}{lllll}0.15 & 0.34 & 0.25 & 0.23 & 0.03\end{array}\right)$ in the period is gotten, and then the influent degree $\mathrm{C}_{f_{2}}=\mathrm{H}_{2} V^{T}=0.43$ in this period is also found.

Such the risk factor in construction period is $R_{f 2}=P_{f 2}+C_{f 2}-P_{f 2} C_{f 2}=0.63$.

By using the same method the risk factor $R_{f l}=0.55$ in recognition period, $R_{f 3}=0.49$ in operation period, and $R_{f t}=0.34$ in termination period can be found. The weights in the first layer of subsystem $A=\left(\begin{array}{llll}0.3 & 0.2 & 0.3 & 0.2\end{array}\right)$ though analytic hierarchy process can be found too. So the total risk factor of the virtual enterprise's project is as follows:

$$
\begin{aligned}
R_{f} & =\sum_{i=1}^{n} R_{f i} A_{i} \\
& =0.55 \times 0.3+0.63 \times 0.2+0.49 \times 0.3+0.34 \times 0.2 \\
& =0.506
\end{aligned}
$$

According to the assessment rule above, the total risk factor of the virtual enterprise's project is between 0.3 and 0.7 , so the risk of this project is belong to the middle degree.

The above fuzzy comprehensive evaluation method model based on the risk factors makes the enterprise's risk become measured, and helps the decision maker very much. It is benefit for decision maker to find where the key risk is and to take efficient measures to reduce the risk loss.

\section{Conclusion}

Aiming at the character of complexity, fuzziness and uncertainty, this paper proposed the fuzzy comprehensive evaluation model based on the risk factors. From the above example, the fuzzy comprehensive evaluation method based on the risk factors can estimate the total risk degree of the virtual enterprise's projects, and get an intuitional measurement value which can help the decision maker a lot. Compared with other assessment methods, this one is simple and easy to be understood.

However, the method in this paper also has its limitation. For example, it can't give a detailed explanation about the core of the risk factor to the virtual enterprise's risk. So after the decision-making of using the risk factor assessment method, it still needs to do fine-analysis to the virtual enterprise's project risk to find out where the key risks are, and then to take effective measures to avoid and control the risk loss.

\section{References}

1. W.D. Feng and J.Chen, Study on Risk Analysis and Monitoring within Virtual Enterprises, Chinses Journal of Management Science, 05, (2001).

2. D.M. You and W. Pen, Study on Risk Monitoring in Virtual Enterprises, Journal of HuNan Economic Management College, 10, (2003). 
66 Risk Assessment of Virtual Enterprise Based on the Fuzzy Comprehensive Evaluation

Method

3. Z.b. Zeng, Y.L. Li and j. Shu, Risk Appraisal Based on Fuzzy Multi-Attribute Decision for Virtual Enterprise Formation, Computer Engineering and Applications, 4,(2006).

4. M. Huang, F.E. Li and X.W. Wang, PERT Based Risk Evaluation Model for Virtual Enterprise, Journal of Northeastern University (Natural Science), 9(9) , (2005).

5. R.N. Nagel etc, 21st Century Manufacturing Enterprise Strategy, Iacocco Institute, Lehigh University, Bethehem(1992).

6. G. Martha, H.R. Karlene, Risk Mitigation in Virtual Organizations, Organization Science, 10(6):704-721(1999).

7. Y.L. Wang, The 21 st Century Oriented Production Model and Its Management, Journal of XiAn JiaoTong University, 1-4, (1997).

8. Z.m. Li, G. Du and Z. Li, Risk Recognize Index Systemand and Evaluation Model in Virtual Enterprises Based on Life Cycle, Journal of Xidian University(Social Sciences Edition),3(2),(2006).

9. Z.B. Zhao, Analysis on the life cycle and risk management of virtual enterprise, Technoeconomics \& Management Researc, h 3, (2003).

10. Zhao H.f., QiuW.h., WangX.z., Fuzzy Integrative Evaluation Method of the Risk Factor. Systems Engineering-Theory \& Practice, 1997, 17(7)

11. J. Li, Application of Fuzzy Integrative Evaluation Method to Risk Management of Virtual Enterprises, Industrial Engineering Journal, 5(3), (2004).

12. L.F. Wang and S.B. Xu, An introduction to the analytic hierarchy process, China Renmin university press, Beijing(1996). 